\title{
Idealismo racional: a aproximação Reinholdiana do realismo lógico
}

\author{
Rational idealism. Reinhold's \\ aproximation of logical realism
}

Federico Ferraguto*

Pontifícia Universidade Católica do Paraná (PUCPR), Curitiba, PR, Brasil

\section{Resumo}

Neste artigo, visamos reconstruir o percurso que leva Reinhold ao realismo lógico de Bardili que caracteriza a perspectiva assumida nos Beyträge zur leichtern Übersicht des Zustandes der Philosophie beym Anfänge des XIX Jahrhunderts. Através de uma reconstrução da reflexão reinholdiana acerca da relação entre filosofia e entendimento natural, e acerca do estatuto da reflexão e da abstração, mostramos como Reinhold, apesar das mudanças que ocorrem ao longo da Briefwechsel com Bardili no começo de 1800, não consegue se afastar completamente das exigências de justificação transcendental que inspiram a doutrina da ciência de Fichte. Após uma apresentação da reflexão reinholdiana do problema da relação entre especulação e senso comum (§ 2), analisamos alguns trechos das cartas que Reinhold troca com Bardili nos primeiros meses de 1800 (§§ 3-4), concluindo com algumas indicações a respeito das aderências transcendentais presentes também na proposta reinholdiana do realismo racional (§5).

Palavras-chave: Reinhold. Filosofia transcendental. Realismo. Fichte. Reflexão.

*FF: Doutor em Filosofia, e-mail: federico.ferraguto@pucpr.br 


\section{Abstract}

The paper aims a reconstruction of the path that leads Reinhold to the logical realism of Bardili, which characterizes the perspective assumed in the Beyträge zur leichtern Übersicht des Zustandes der Philosophie beym Anfänge des XIX Jahrhunderts. Through a reconstruction of Reinholdian reflection on the relationship between philosophy and natural understanding and the status of reflection and abstraction, the paper shows how, despite the changes that occurred during the Briefwechsel with Bardili in the early 1800s, Reinhold cannot completely away from the demands of transcendental justification that inspire Fichte's transcendental philosophy. After a presentation of Reinhold's reflection on the relationship between speculation and common sense (\$2), the article analyzes some passages of the letters that Reinhold exchanged with Bardili in the early months of 1800 (\$§ 3-4), concluding with some indications transcendental adherences also present in the reinholdian proposal of rational realism ( $(5)$.

Keywords: Reinhold. Transcendental philosophy. Realism. Fichte. Reflection.

\section{Um junco ao vento}

Graças ao consistente desenvolvimento da pesquisa mais recen$\mathrm{te}^{1}$, parece impossível reduzir o pensamento reinholdiano a uma versão mais atualizada e mais fundamentada do kantismo, assim como a uma simples preparação da doutrina da ciência ${ }^{2}$. Trata-se de uma consideração banal que, mesmo assim, tem que continuar lidando com a ideia clássica, de que Reinhold seria um junco ao vento, e que as mudanças de perspectiva no pensamento dele seriam pela incapacidade de compreender, de modo aprofundado, as perspectivas sistemáticas que ele abraça, até passar no terreno da filosofia popular e do ecletismo ${ }^{3}$. Na verdade, as variadas mudanças no pensamento de Reinhold nunca são imediatas e desacompanhadas de um certo tormento. Reinhold é

1 Para uma descrição das linhas de desenvolvimento da pesquisa sobre Reinhold, cf. Ivaldo, 2008 e Valenza, 2005.

20 primeiro responsável deste esquema interpretativo foi o próprio Fichte, o qual continuou sendo válido até os últimos anos, logo no começo da Begriffschrift de 1794. Cf. Fichte, 1962-2013, l, 2, p. 109-110.

3 Este juízo também foi formulado por Fichte, no Antwortschreiben de 1801. Cf. por ex. Fichte, 1962-2013, I, 7, pp. 209 e 217. 
um autor muito sensível aos deslocamentos da discussão pós-kantiana e um verdadeiro termômetro do debate sobre as implicações do criticismo. Autêntico historiador da filosofia, de fato, ele toma distância dos sistemas filosóficos que ele aborda, para avaliá-los não com base na evidência que um certo sistema possui aos olhos de quem o cria, e sim em relação à "possibilidade e à peculiaridade autêntica de um outro descoberto depois do deles" (BLU, V, p. 28). Tudo em função de uma única tarefa, comum a toda pesquisa filosófica. Esta tarefa seria a mesma daquela que Reinhold escreve no começo dos Beyträge de 1801, sobre a verificação e o acerto da realidade do conhecimento a partir da sua fundação (BLU, V, p. 45). Tal tarefa permite justificar as mudanças do sistema filosófico, além de alegar que nem Kant, nem Fichte, e tampouco Schelling teriam conseguido fundar o conhecimento sobre uma base incontestável de realidade ${ }^{4}$, a qual não tem de ser demonstrada na filosofia, mas sentida no horizonte definido pelo entendimento natural.

O realismo bardiliano conseguiria realizar esta fundação, porém, para Reinhold, duas questões ficariam abertas: a primeira tem a ver com o processo fundacional da filosofia. Para Reinhold, de fato, a tarefa primeira da filosofia não envolve a realidade em si do conhecimento, e sim a sua averiguação e justificação. Mas como pode acontecer uma justificação deste tipo sem uma previa justificação do ato epistemológico do conhecer? (BW, p. 116). A segunda questão é sobre a relação da filosofia com o senso comum. Mesmo que uma descontinuidade tenha que ser admitida entre o percurso da filosofia e a imediata percepção da realidade que se encontra no senso comum, como não entender a filosofia como uma atividade enraizada no próprio senso comum? Ao longo deste artigo, tentaremos mostrar como estes dois problemas definem a apropriação reinholdiana do realismo lógico. Após uma apresentação da reflexão reinholdiana do problema da relação entre especulação e senso comum (§ 2), analisaremos alguns trechos das cartas que Reinhold troca com Bardili nos primeiros meses de 1800 (§§ 3-4), concluindo com algumas

4 De fato a filosofia de Schelling está entendida como uma espécie de regressão na resolução da tarefa fundamental da filosofia (BLU, V. 45). Sobre as criticas de Reinhold a Schelling cf. Bondeli, 1995, p. 323-329. 
indicações a respeito das aderências transcendentais presentes também na proposta reinholdiana do realismo racional (§ 5).

\section{0 paradoxo da filosofia}

É notório que com a adesão à doutrina da ciência de Fichte, Reinhold pretende oferecer à filosofia uma base prática mais rigorosa e, por outro lado, avançar na dedução genética do próprio princípio do saber contra as objeções levadas pelo próprio Fichte, mas também por Schulze e Maimon. A fundação prática da doutrina da ciência tinha que satisfazer à exigência de conciliar a imediatidade das convicções do entendimento natural e o aspecto genético típico da fundação de uma ciência filosófica baseada em um princípio, como aquele que Reinhold já tinha admitido no ensaio: Sobre a diferença entre o entendimento saudável e a razão filosofante, que abria os Beyträge de 1794. Para Reinhold, a filosofia seria autêntica apenas à medida que prova o sentimento de universalidade e necessidade, que identifica o entendimento natural e o distingue da investigação filosófica (REINHOLD, 2004, p. 25-26). A filosofia tem que mostrar, com provas irrefutáveis, a universalidade e a necessidade dos sentimentos do entendimento comum, mas não os produzir. Entendimento comum e filosofia procedem até um fim comum, o alcance do qual implica a impossibilidade de uma ilegitimação recíproca. O nó que as liga pode ser dissolvido, ou seja, tornado invisível perante os ataques dos céticos, mas não pode ser trancado ${ }^{5}$. Na fase de adesão à doutrina da ciência, e em especial nos escritos sobre os Paradoxos da filosofia mais recente, Reinhold, ao tentar esclarecer, torna ainda mais complexa a coparticipação entre filosofia e senso comum. Para o filósofo, de fato, todo o desenvolvimento da filosofia crítica, inclusive a de Fichte, seria caraterizado por um paradoxo. A filosofia apresenta-se como especulativa, ou seja, como produto artificial do entendimento. Mas, ao mesmo tempo, ela assume a liberdade como princípio fundamental. A liberdade, porém, não pode ser produzida e alcançada

Reinhold, 2004, p. 4 e p. 6, onde parece evidente uma referência para Schulze. Sobre 0 impacto do ceticismo no desenvolvimento da filosofia elementar cf. Fincham, 2000. 
através de uma dedução. Ela tem que ser imediatamente sentida e alcançada pelo próprio sujeito (PNP, p. 29-30). Assim, ou se entende a liberdade de um ponto de vista intelectualista e ela permanece um arbítrio egoístico, ou se admite que a liberdade é indemonstrável na filosofia, quebrando a coerência e unidade desta última (PNP, p. 34). Paradoxal, de fato, é uma expressão equívoca, refletida por um acordo falho em si mesmo (PNP, p. 43), e ainda um juízo onde verdade e aparência de verdade estão misturadas (PNP, p. 43-44). Estas afirmações não têm que ser entendidas apenas em um sentido negativo, e sim como expressões de uma abertura estrutural do entendimento natural. Este último, de fato, não concebe essas expressões como completamente verdadeiras, pois não refletem uma convicção imediata. Por outro lado, não as concebe como completamente falsas, uma vez que consegue pensá-las. Uma autêntica filosofia, contudo, tem de conseguir ultrapassar este paradoxo e dissolvê-lo por meio de um progresso reflexivo (PNP, p. 46). A filosofia não visa fundar uma convicção diferente da do entendimento natural. Ela tem que voltar para a convicção dele e reconstruí-la como expressão de um pensar autônomo, da liberdade do nosso querer e, por fim, não como expressão daquilo que é, e sim do que tem que ser (PNP, p. 52-53). De fato, tanto a convicção que caracteriza o entendimento natural, como a que fica na base da especulação, têm uma raiz comum, ou seja, um sentimento moral que liberta o homem dos vínculos naturais e o torna consciente de sua liberdade (PNP, p. 60).

No entanto, enquanto a consciência natural se liberta da natureza por um sentimento imediato, a filosofia é caraterizada por um movimento duplo: a) olha e percebe o mundo, b) intuiciona-o pela abstração da percepção. A convicção típica da especulação não estaria baseada na superação da experiência, mas na dupla operação de sua abstração e reflexão. A liberdade da filosofia, por conseguinte, não surgiria da experiência para atuar sobre ela, como liberdade do querer, mas apenas como liberdade de construir um saber puro, por si mesma e a partir de si mesma. Assim, através da autodeterminação absoluta da liberdade, o filósofo realiza um pensamento autônomo e artificial, o que não pode ser realizado no âmbito do entendimento natural, que se apoia apenas nos conceitos tirados da própria experiência. Mas o filósofo não pode se esquecer que ele permanece sempre como um indivíduo. “Não pode se 
esquecer que em todo o tempo futuro, nem ele, ou qualquer outra pessoa poderia esgotar o saber puro; e o que está pressuposto na realização de todo puro saber, nunca poderia ser obtido por meio do seu saber puro" (PNP, p. 87-88). Portanto, sob o perfil especulativo, nunca se poderá considerar completamente livre. A liberdade pode ser afirmada apenas do ponto de vista prático. Nesta perspectiva, não é possível abstrair infinitivamente da experiência de objetos. A consciência estaria vinculada a um único "objeto absoluto", mas não através da percepção, e sim por meio da fé. Isso significa que, do ponto de vista da filosofia, esse objeto tem que ficar no plano do ideal, assim como a verdade a que essa certeza está ligada. A filosofia, porém, nunca pode ser puramente idealista, nem puramente realista. Não pode ser realista porque ela tem que olhar além da experiência. E não pode ser idealista porque, mesmo abstraindo da experiência, a liberdade que a torna possível ou a afirma, o faz imediatamente pela consciência natural. Assim, do mesmo modo, também a expressão "idealismo transcendental" só pode ser um paradoxo, pois ela faz sentido apenas em relação ao que é absolutamente diferente dela, isto é, ao entendimento natural. Entretanto, a natureza paradoxal da filosofia não pode significar que ela tenha de ser negada; nem se pode alegar que, em nome da certeza imediata garantida pelo entendimento natural, Reinhold esteja se afastando da anterior exigência expressa na filosofia elementar, a saber, a de fornecer uma visão filosófica da realidade fundada em um princípio único. É verdade que Reinhold, no mesmo período em que escreve as Paradoxien, diz em uma carta a Baggesen que a sua aproximação à filosofia de Fichte seria apenas expressão de uma exigência de fundação formal, enquanto a verdade material, que a fundamenta e que coincide com a certeza imediata do entendimento natural, tem que ser separada da consciência filosófica, assim como os valores morais que a definem (BAGGESEN, 1831, p. 166-167). Mas, igualmente, o próprio Fichte, tanto nos primeiros escritos da época de Jena como na Primeira e Segunda introdução à doutrina da ciência, escreve que a filosofia tem que se fundamentar em um pressuposto extra filosófico, tanto do ponto de vista formal como do material. Do ponto de vista formal, o fundamento da filosofia fica sempre fora da própria filosofia, a qual tem a tarefa não de reduzi-lo a si mesma, e sim de desenvolvê-lo a partir de si mesma, 
tirando todas as implicações envolvidas nele (FICHTE, 1962-2014, I, 2, p. 115); e do ponto de vista material, não é possível realizar uma compreensão filosófica sem uma convicção puramente subjetiva e individual, que tem a ver justamente com os valores que a orientam, já que, como sabemos, para Fichte, "a filosofia que se faz depende do homem que se é" (FICHTE, 1962-2014, p. 195). Para ele, essa realidade é garantida pela intuição imediata da autoatividade do sujeito. Mas para Reinhold, esta conclusão não parece ser suficiente, pois a intuição da autoatividade é entendida como um fato da consciência (Thatsache des Bewustseins), no qual se anuncia a lei moral. E este fato da consciência é a realidade fundamental em que a filosofia tem que se basear, porque a filosofia não é senão uma decomposição deste fato no conjunto das operações da própria consciência concreta. Para Reinhold, a conclusão de Fichte possui duas consequências: uma é que a intuição da autoatividade da consciência pressupõe uma intuição sensível, o que tornaria a afirmação da realidade básica do pensamento algo que não ultrapassa a experiência, mas apenas a pressupõe. A outra é porque a apresentação da lei moral, que há na intuição intelectual, só diz respeito à coerência e à autonomia da consciência concreta, mas não indicaria a realidade fundamental que fica por trás da própria lei moral. Portanto, deixar coincidir o princípio da realidade com a autoatividade do sujeito, significaria pôr as bases para uma dedução da liberdade admitida pelo entendimento natural a partir de determinações tiradas do saber puro. Isto indicaria justamente uma troca entre a exigência de ir além da experiência através da afirmação da liberdade como princípio do real, e a de tirar desta afirmação um conjunto de determinações necessárias, que fazem sentido apenas dentro do próprio saber, perdendo, de antemão, a origem real do próprio saber filosófico. Os dois planos deveriam ser conciliados, mas não misturados. É justamente esta possibilidade que Reinhold pensa encontrar no realismo lógico de Bardili, um realismo baseado na negação da legitimidade da síntese entre pensamento e intuição. 


\section{Idealismo racional}

Sem recusar completamente sua adesão inicial ao kantismo, Reinhold busca, então, uma posição intermediária entre o realismo de Jacobi e as tendências supostamente idealistas em que o kantismo estava se desenvolvendo, ou seja, entre a valorização do senso comum e a exaltação das potencialidades da razão, encontrando um ponto de apoio fundamental no Grundriss der ersten Logik (Compêndio de lógica primeira). Baseando-se no realismo lógico de Bardili, Reinhold pretende conciliar a espontaneidade do pensamento e a realidade absoluta do seu objeto em um conceito unitário, extenso e pré-subjetivo da razão ${ }^{6}$. Apesar das formulações mais explícitas, que há nos Beyträge de 1801-1803, a aproximação de Reinhold ao realismo lógico só aparentemente é uma crítica à doutrina da ciência de Fichte. Tanto na auto interpretação que Reinhold oferece do seu pensamento no Tomo $\mathrm{V}$, como na interpretação da filosofia crítica oferecida nas Paradoxien, podemos encontrar elementos que permitem entender a operação filosófica reinholdiana como uma tentativa de conciliar o realismo do entendimento natural sistematizado pelo realismo lógico bardiliano, e o idealismo que, para Reinhold, assim como para Fichte, representa o marco fundamental de todo empreendimento filosófico. Esta ideia encontra-se confirmada também nas cartas trocadas por Reinhold e Bardili entre 1800 e 1803, e publicadas pelo próprio Reinhold em 1804, com o título de Briefwechsel über das Wesen der Philosophie. Estas cartas representam um verdadeiro laboratório que, por um lado, Reinhold elabora o seu re-pensamento do realismo lógico bardiliano e, por outro, Bardili reivindica uma impostação filosófica contra toda possibilidade de aproximá-lo do idealismo da doutrina da ciência. Justamente em uma destas cartas (janeiro de 1800), Reinhold copia para Bardili um trecho de uma carta anterior endereçada a Fichte, onde alega que o próprio Bardili não seria um adversário da doutrina da ciência. De fato, na visão de Bardili, haveria "elementos específicos" de que ele "vagueia apenas nos conceitos fundamentais", mas, assim que fossem sistematizados de modo mais claro, dariam uma "exposição completamente nova do idealismo transcendental

6 Para uma descrição ampla dos objetivos das Contribuições de Reinhold, cf. BONDELI (1995). 
ou, mais apropriadamente, a sua criação (Erfindung) em uma via nova e completamente diferente" (BW, p. 82-83).

Não é por acaso que, logo depois de ter afirmado a proximidade entre o realismo lógico e doutrina da ciência, Reinhold acrescenta que o próprio Fichte justificaria a possibilidade de re-inventar ou re-criar o sistema da doutrina da ciência, de um ponto de vista completamente diferente, pois "esclareceu as variadas exposições da essência da especulação, como algo valioso para o desenvolvimento da ciência” (BW, 83). Ademais, o filosofar não é apenas um exercício que pode ficar sedimentado em um livro ou em palavras, mas representa o fruto de uma ação ou de uma prática reflexiva que tem que se renovar constantemente, e que, mesmo mantendo os seus objetivos e as suas regras fundamentais, sempre pode encontrar formulações diferentes (FICHTE, 1962-2014, I, 2, p. 143-145). O realismo lógico bardiliano, portanto, teria o mesmo objetivo e respeitaria as mesmas regras de todo empreendimento filosófico rigoroso e coerente (inclusive o da doutrina da ciência).

Antecipando uma crítica de Fichte, Reinhold escreve que o ponto central, pelo qual o sistema bardiliano pode ser entendido, consiste na sua "nova definição do pensar como pensar", que certamente tem "desvelado as contradições da lógica que tivemos até agora". Porém, ao mesmo tempo, é também verdade que o conceito pressuposto na fórmula "pensamento como pensamento (Denken als Denken)", não foi entendido na sua relação com o conceito ordinário de pensar como uma mera atuação subjetiva baseada nas ações do refletir e abstrair (BW, 71). Não obstante, uma identificação do conceito bardiliano de pensar com o ordinário implicaria uma identificação incorreta entre pensar e contar, uma impossibilidade de entender a verdadeira natureza da repetição, que caracteriza o próprio pensar e, por fim, uma confusão entre o infinito teorizado no âmbito do realismo lógico e o teorizado pela matemática. Ao mesmo tempo, as ações do refletir e do abstrair, que são necessárias também pelo desenvolvimento do realismo, ficariam identificadas com o produto de uma mera atuação subjetiva (BW, 73). Tona-se, portanto, necessário repensar os elementos fundamentais do realismo racional e mostrar como ele, mais do que uma contraposição radical, representaria uma espécie de superação ou suprassunção da filosofia crítica. 
Este re-pensamento do realismo lógico, cuja primeira versão Reinhold oferece a Bardili na carta de Janeiro de 1800, refere-se justamente sobre o estatuto de reflexão e abstração. No mesmo sentido defendido por Fichte na Begriffschrift, a reflexão e a abstração são vistas como duas atividades inseparáveis da consciência (BW, p. 78; Fichte, 1962-2014, I, 2, p. 143). Em Reinhold, a identidade fundamental do pensamento é, por assim dizer, levada à consciência por meio da reflexão e da abstração. Ele diz: "não tem visão do uno como uno sem um desviar o olhar do outro, na consciência" (BW, p. 78). Isto significa que, entre a unidade do pensamento e sua tradução na consciência reflexiva e abstrativa, tem um deslocamento que marca uma diferença fundamental entre a perspectiva de Bardili e a fichteana. $O$ pensamento não é definido pela reflexão e abstração, ao contrário, são elas que permitem que todo acesso à unidade da consciência seja apenas relativo e que ocorra pela relação entre um em-si e um outro. Em outras palavras, a filosofia não pode ter um acesso direto à unidade fundamental que justifique e motive suas aplicações teóricas e práticas (BW, p. 78). Assim como Fichte tem sustentado que a filosofia é apenas atuação limitada de uma vitalidade intrínseca ao espirito humano (FICHTE, 1962-2014, I, 5, p. 426), o realismo, assim que é tornado objeto de um olhar abrangente pela reflexão filosófica, pressuporia um deslocamento fundamental no cerne da realidade. A abstração e a reflexão representam, portanto, a mera forma externa do pensamento. Supondo que, deste ponto de vista, se pudesse falar algo a respeito do próprio pensar, teria que se supor também a necessidade de sempre fazê-lo pressupondo que a língua que o expressa reflita apenas a sua constituição exterior, e não a sua essência interior. Em termos ainda mais específicos: toda afirmação sobre a constituição interna do pensamento pressupõe que ele não fora formulado a partir do ponto de vista do próprio pensamento, e sim da sua aplicação, ou seja, da sua inclusão em uma dinâmica relativa e reflexiva que, por assim dizer, torna-o conteúdo de uma consciência.

Para compreender o inteiro processo de repetição do pensamento-uno nos atos concretos de pensamento, Reinhold considera essencial diferenciar entre forma interna e forma externa do pensamento. De fato, uma coisa é compreender a unidade que doa sentido ao pensar 
como pensar; outra coisa é concretizar esta unidade através da abstração e da reflexão em tomadas de posição efetivas e juízos específicos. A possibilidade de encontrar a unidade fundamental que doa sentido a todo ato subjetivo - e arbitrário - de tematização de um objeto (ou de um certo aspecto de um objeto), representa a resposta e a aplicação reinholdiana da identificação entre construção de uma metafísica e satisfação das necessidades do senso comum, que Bardili, na segunda carta do Epistolário, considera o pressuposto fundamental para a formação da perspectiva realista. Para Bardili, o realismo, ou seja, a demonstração de um nível da realidade não contraditório e extra subjetivo, está relacionado a uma "lei fundamental do ser", a qual permitiria afirmar o ser de um objeto para além de toda interpretação subjetiva (BW, 41-42), e satisfazer uma pretensão de alcance da realidade que não pertence ao entendimento, e sim a uma necessidade do coração (BW, p. 18). Para Reinhold, trata-se de evitar uma troca entre a pressuposição justificada de um ser interior a todo ato de pensamento e a forma externa em que este ser interior fica exposto. De fato, trocar uma coisa por outra significaria "cometer o mesmo erro fatal que a filosofia vinha cometendo até agora" (BW, 78).

É justamente esta distinção que, para Reinhold, forneceria um critério para diferenciar o conhecimento natural e o saber filosófico. O primeiro consiste em uma reflexão sobre algo dado e se desenvolve no âmbito da aplicação do pensamento, isto é, do pensar como pensar. O pensamento lógico, expresso por Kant na primeira $\mathrm{Cr}^{1}{ }^{1} \mathrm{Ca}^{7}$, representa o conjunto (ou o cânon ${ }^{8}$ ) para que este pensamento natural possa se desenvolver (BW, 80). Diferentemente seria com o saber filosófico, que surge a partir do pensamento como pensamento e busca, por meio da reflexão e da abstração sobre o que é dado pela aplicação do pensamento, o "puro verdadeiro" ${ }^{\prime}$, logo, no conhecimento natural.

Alinhado com a perspectiva das Paradoxien, Reinhold caracteriza o conhecimento filosófico com o que tem que se desvencilhar de um dado pressuposto, e com o que tem de se desenvolver, "através

\footnotetext{
Cf. por exemplo B, IX.

B, 26.

9 Não seria 0 "puro e verdadeiro pensamento"?
} 
da fantasia", em um horizonte ignoto, por assim dizer. Assim, "por meio da fantasia, o pensamento filosófico tem que anular tudo o que há na aplicação originária do pensamento, que não é pensamento, para chegar à forma do pensamento". E, através desta variação fantástica, conseguir uma multiplicidade baseada na pura forma do pensamento. Então, o pensamento filosófico tem que tematizar o que o conhecimento natural apenas sente, e o guia nas suas tomadas de posição. Já o saber filosófico não sente nada, mas leva à consciência a própria unidade absoluta do conhecimento natural: "O idealista, enquanto tal, conhece a verdade apenas em abstrato, enquanto o realista a conhece em concreto. Contudo, certamente o filósofo tem que pressupor um sentimento da verdade. Mas, por outro lado, o realista, que se deixa conduzir por este sentimento, tem que apreender a reconhecê-lo" (BW, 82).

O ganho de Reinhold com esta diferenciação se apresenta em duas consequências fundamentais. A primeira, e mais uma vez na mesma linha das Paradoxien, é que esta dinâmica permite esclarecer de qual maneira é possível passar do pensamento para o pensamento como pensamento e ainda esclarecer a raiz dos erros que permitem a troca entre filosofia e consciência natural. A segunda consiste no fato de que, uma vez definida uma continuidade entre pensamento e aplicação, ou entre idealismo e realismo, não haveria mais necessidade de contrapô-los. Mais do que uma contraposição, seria formar uma coalisão entre as duas abordagens, a realista e a transcendental. Por conseguinte, não parece necessário propor mais uma alternativa entre realismo lógico e idealismo transcendental, mas sim conceituar uma síntese dos dois em um "idealismo racional", ou seja, em um idealismo consciente dos seus limites, que respeite a pretensão de realidade típica do realismo da consciência natural e, ao mesmo tempo, permita visualizar esta pretensão por meio das faculdades de variação fantástica, isto é, da abertura de um horizonte infinito e desvencilhado de toda vinculação sensível, próprio da filosofia (BW, 83). 


\section{Do idealismo racional ao realismo racional}

A crítica de Fichte na resenha do Grundriss, e também a discussão do Grundriss e a influência de Jacobi, motivam a reação de Reinhold diante do posicionamento do autor da doutrina da ciência ${ }^{10}$. Esta reação tem implicações ligadas tanto à colocação da perspectiva reinholdiana no debate sobre a filosofia de Kant no limiar do século XIX, quanto no que diz respeito ao desenvolvimento de precisas questões teóricas envolvidas no realismo lógico bardiliano ${ }^{11}$. É justamente Bardili que alerta Reinhold sobre uma questão fundamental, que coloca em questão toda a impostação do suposto idealismo racional, vaguejado por Reinhold na carta de 13 de janeiro. Vimos, como na primeira interpretação do Grundriss, que Reinhold considerou a abstração e a reflexão como dois meios capazes de tornar possível a manifestação na consciência. Ambas, de fato, tornavam possível a aplicação e a manifestação do pensamento na consciência. Abstração e reflexão provocam uma autorrelação do pensamento como pensamento, favorecendo, assim, uma intepretação muito próxima da Tathandlung fichteana (BW, p. 84). Na filosofia de Fichte, a identidade do eu com si mesmo não é apenas uma identidade, mas a passagem da consciência imediata ao pôr a consciência concreta do ser posto da própria identidade no pensamento.

Isso significa que, para Fichte, a reflexão e a abstração desempenham um papel mediador fundamental para que o pensamento não seja apenas princípio, mas sim justificado enquanto tal. Na sua primeira interpretação do Grundriss, Reinhold não retoma explicitamente o argumento de Fichte expresso no $\S 7$ da Primeira introdução, que parece estar a reboque da distinção que o próprio Reinhold estabelece entre consciência comum e filosofia. A filosofia, graças à imaginação, consegue ir além da realidade empírica e abrir um horizonte diferente, real, mas ao mesmo tempo imune das contradições e imprevisibilidades que

10 Cf. sobre isso, a interpretação de Valenza, 2003, p. 145-160. Valenza tende a acentuar a motivação prática que leva Reinhold a tomar distância da doutrina da ciência. No entanto, conforme buscaremos mostrar neste parágrafo, Reinhold parece intentar um re-pensamento da doutrina da ciência que tem, ao mesmo tempo, uma base teórica e prática, justamente no sentido de Fichte, conforme não é possivel separar dimensão teórica e dimensão prática da reflexão filosófica.

11 Tenho desenvolvido estes dois elementos da relação entre Fichte e o realismo racional em Ferraguto, 2015a e Ferraguto, 2017. 
Bardili tinha encontrado na lógica de Kant. A abordagem de Reinhold parece antecipar e neutralizar as críticas formuladas por Fichte, segundo a qual não seria legítimo admitir o pensamento como princípio do real, sem uma justificação do "quem" pensa o pensamento e o admite como princípio. De acordo com Fichte, a relação entre pensamento concreto e sua lei tem que ser extra discursiva, remontar em um princípio, mas este princípio tem que envolver a sua justificação. Sobretudo, trata-se de uma abordagem relevante, pois, pelo menos em um sentido explicito, distingue dois níveis do filosofar: o da justificação da asserção filosófica, que até poderia se desenvolver a partir das premissas de um idealismo, com os instrumentos do transcendentalismo. E o da "realidade" do próprio princípio que o fundamenta, a qual tem que ser imediatamente afirmada e irrefutavelmente sentida pelo ser humano. Filosofar, conforme Reinhold escreve no primeiro tomo dos Beyträge, consiste na fundação da realidade do conhecimento, ou em termos ainda mais claros, em fundar a verdade e a certeza, entendidas como resultados da averiguação e manifestação da realidade no conhecimento (BLU, I, p. 2). Esta fundação é entendida como resultado de uma tarefa que realiza, e ao mesmo tempo modifica, o que chamamos de realidade do conhecimento. A pré-compreensão da filosofia, entendida como um processo onde a realidade do conhecer se manifesta, tem que se harmonizar com a compreensão e a justificação do seu manifestar-se a partir da sua inevitável modificação pela máxima, através da qual o próprio filósofo conceitua a tarefa da fundação ${ }^{12}$. Esta é a possibilidade de encontrar, na relação entre realidade pré-compreendida e conceituação, a tarefa do filosofar, que define o critério da sustentabilidade - da verdade ou falsidade - do próprio filosofar, o que proporciona que a verdade se manifeste de forma científica (BLU, I, p. 4). É evidente a herança kantiana na definição desta estrutura conceitual ${ }^{13}$. No entanto, de modo diferente de Kant, Reinhold não visa definir um critério formal e material, negativo ou positivo da verdade, mas que a verdade do princípio seja capaz de irradiar verdade e realidade ao completo sistema

12 Como base para avaliar a função de Reinhold como historiador da filosofia, conferir o argumento de Valenza, 1994.

13 Cf. AK, IX, 51-53; KrV, A 58, B 89.

Rev. Filos., Aurora, Curitiba, v. 30, n. 51, p. 645-668, set./dez. 2018 
da filosofia. A réplica de Bardili a esta impostação é, porém, decisiva e capaz de colocar em crise todo o dispositivo conceitual reinholdiano desta fase. Na prossecução da sua carta em resposta a Reinhold, em 4 de fevereiro de 1800, Bardili esclarece que:

Em geral, o Senhor fala da reflexão como condição do pensamento na consciência como consciência. Ao contrário, conforme a minha teoria, o que é condição do pensamento, ou numa expressão mais adequada, o que é fundado absolutamente pelo pensamento como pensamento [...] está aplicado à matéria formalmente, e através da forma da matéria, a própria forma (BW, p. 100).

Na verdade, tanto é impossível aplicar o pensamento diretamente à matéria, quanto aplicar uma forma subsistente por si mesma. Pode-se aplicar apenas o pensamento à forma, como forma da matéria. Em outras palavras, é necessário subordinar a matéria à sua forma para que nesta forma sejam geradas, pela imaginação, e a partir do pressuposto do pensamento, as estruturas que determinam a nossa compreensão do mundo (coexistência, oposição, afinidade etc.). "A matéria sempre é decomposta pelo pensamento e, conforme expressei-me no Grundriss, para quê e até o ponto em que a matéria não possa irromper e se manifestar" (BW, p. 101). Dessa forma, é o próprio pensamento que se aplica à matéria e constitui a base para as formas serem desenvolvidas pela imaginação. Mas não é, como queria Reinhold, a própria imaginação, através da reflexão e da abstração, a provocar esta aplicação. Em outras palavras, Reinhold ficaria kantiano demais ${ }^{14}$. Na ótica de Bardili, a construção de formas abstratas é possível apenas a partir da "formação", ou seja, da sublimação ou anulação da matéria através do próprio pensamento, independentemente de toda relação com

14 Para Kant, a aplicação pressupõe a heterogeneidade do pensamento e do mundo fenomênico. Eé esta heterogeneidade que torna possível o juízo que, conforme observa Fichte na resenha do Grundriss, precede e funda o pensamento (B 177-178). Para Kant, 0 esquema transcendental, entendido como algo "intermediário que liga as categorias à sensibilidade", é sempre um produto da imaginação (B 170; A 140), que constrói não um objeto, e sim uma forma ou uma regra para compreendê-lo. 0 esquematismo, porém, não é um elemento intrínseco à realidade, nem um traço estrutural da natureza. 0 esquematismo é, muito mais, uma "arte escondida no fundo da alma humana" (A 142), que representa, na economia do realismo lógico, 0 índice da separação fatal entre mente e mundo, própria de toda filosofia não consequente (Cf. FERRAGUT0, 2015b). 
qualquer atividade específica do espírito humano (BW, 101). Bardili expressa esta dinâmica em uma longa fórmula. Conforme "toda reflexão no seu conceito fundamental, como reflexão geral representada primeiramente pela fórmula $(A+C)$ posto in $(B-B+C)$ ". Isso significa que a reflexão representa a unificação do pensamento $(\mathrm{A})$ e da matéria (C) em uma construção em que a forma (B) se anula como independente $(B-B)$, mas mantém o fato de ser forma de uma matéria. Em outras palavras, e sem esclarecer explicitamente a dinâmica, trata-se de repensar o conceito de reflexão não mais em termos transcendentais, e sim em termos metafísicos, e no mesmo sentido de Ploquet, quem inspirou explicitamente o Grundriss ${ }^{15}$. Neste re-pensamento, certamente se mantém uma compreensão da reflexão como expressão de uma separação das determinações do real, com a correlata possibilidade de colocá-las em relação recíproca. Mas esta possibilidade não depende de uma faculdade individual do sujeito filosofante, antes é reconduzida à própria estrutura do real, entendido como expressão de uma racionalidade dinâmica e extra-subjetiva. Em outras palavras, não é o sujeito que possui uma razão, mas a razão que se expressa como ordem de uma realidade (natureza, mundo, valores) da qual o sujeito faz parte. $\mathrm{O}$ fato de que a operação da reflexão de separar e conectar as determinações da realidade pressupõe o conceito kantiano e ploquetiano de antinomia, é cheio de implicações que não podemos analisar neste $\operatorname{artigo~}^{16}$. Porém, vale a pena prestar atenção como este re-pensamento aparece em Reinhold e como ele admite ter dificuldade para se colocar diante do ponto de vista do realismo lógico. Ele assume que a resposta de Bardili tem lançado uma luz nova ao seu pensamento a respeito da relação entre realidade e especulação. Mas, ao mesmo tempo, admite ter se acostumado demais com a especulação fichteana, de cuja reflexão se entende "uma forma de fazer que retorna em si mesmo e como reflexão filosófica justamente aquele fazer, à medida que aparece na consciência do filósofo pela autonomia absoluta" (BW, 111). Apenas depois da leitura do Grundriss e dos esclarecimentos fornecidos pelo próprio

\footnotetext{
15 Sobre a importância de Ploquet neste contexto, cf. Pozzo, 1992, p. 77.

16 Cf. Pozzo, 1992, p. 178-179.
} 
Bardili, Reinhold teria chegado à conclusão de que um conceito de reflexão deste tipo não seria senão um "absurdo filosófico, através do qual teria sido possível a passagem da Wissenschaftslehre à lógica primeira" (BW, p. 116). Ao explicar esta sua tomada de posição, Reinhold admite que o seu conceito de reflexão precedente teria sido vicejado por uma "concrescência" e, em especial, por uma troca imperceptível entre o pensar e o representar, e que teria condicionado a sua distinção entre aplicação originária (o pensar enquanto pensar) e a aplicação filosófica (pensar enquanto pensar aberto pela reflexão). Mas não seria possível, pergunta Reinhold, diferenciar ainda a aplicação como aplicação, tematizada pelo discurso filosófico e aplicação em si própria, válida tanto para a consciência comum como para a filosofia?

Em outras palavras, se a aplicação é apenas uma, como diferenciar o nível de conhecimento oferecido pela filosofia e o da fé do entendimento natural? Para Reinhold, não haveria diferença qualitativa entre eles de modo algum, uma vez que o conhecimento filosófico seria superior ao conhecimento oferecido pelo senso comum. Trata-se, muito mais, de uma diferença quantitativa: o que sentimos na vida ordinária, a convicção fundamental acerca do sentido da nossa própria existência que derivamos de Deus na vida concreta, não poderia ser demonstrado na especulação? Com efeito, "o verdadeiro filósofo", "o homem cheio de respeito por si mesmo, que não apenas conhece Deus teoricamente, mas também do ponto de vista prático, que teme a Deus e o venera, é antes de tudo um homem" (BW, p. 119). Não obstante, continua sendo verdade o fato de que, mesmo não podendo ser entendida como um traço constitutivo de uma "ideia de indivíduo" (BW, p. 120, n.), não podemos ignorar o fato de que aquela compreensão artificial, que chamamos de especulação, não deve ser entendida como instrumento que oferece o conhecimento e a consciência mais clara do pensar como pensar, como o lugar em que Deus se manifesta. E, de modo particularmente próximo do que escreve Fichte, Reinhold continua:

Certamente, o pensar como pensar enquanto tal não é um mero conceito de pensar, mas ele próprio tem que ser (mediado), caro Bardili, pelo pensamento do Senhor, como algo antecedente no Senhor, como um 
indivíduo, como uma consciência que [...] não pode evitar a designação sensível do A, como A, e através do A (BW, p. 122).

Esta mediação inevitável deixaria o pensamento entrar no horizonte da filosofia, e também tornaria necessária a consciência de que se trata sempre e somente de uma mediação. Se o filósofo esquecer isso, perde a consciência da essência da filosofia. Ele se torna um filodoxo e, em especial, um idealista (Ibid.). Esta subtração da mediação oferecida pela designação subjetiva do pensamento como pensamento tornaria possível a elevação, do ponto de vista do pensamento como pensamento, ao âmbito da religião, da fé e do amor, entendido como "emancipação gradativa do gênero humano por meio da vontade de Deus" ou, ainda, como libertação do homem do arbítrio servo, conhecido na época moderna pelo nome de "eu puro, auto atividade, liberdade, razão". Seria este elemento prático a empurrar Reinhold para os braços de Bardili, e fazer com que ele questione o seu transcendentalismo inicial, que parece influenciá-lo na sua primeira recepção do realismo lógico.

\section{A unidade do pensamento e sua aplicação}

Entretanto, na carta de 27 de fevereiro de 1800, Reinhold vincula sua adesão ao realismo lógico à uma pergunta retórica, para a qual entende dar uma resposta positiva. Seu raciocínio, em síntese, é o seguinte: do ponto de vista da consciência comum, não é possível ter uma consciência clara do pensar como princípio estruturante da realidade. A filosofia, mesmo que provisória, oferece uma mediação inevitável. E esta mediação tem que se desenvolver em um sentido transcendental, na forma de uma justificação e de uma legitimação do pensamento concreto do filósofo, como instrumento para conferir à consciência clara do princípio que permite, ao mesmo tempo, a consciência do lugar em que Deus se revela, e a abertura da dimensão da fé e do amor como elementos que libertem a escravidão diante da autonomia da razão.

Do ponto de vista bardiliano, parece evidente, mais uma vez, como o raciocínio de Reinhold reflete a sequência das suas diversas experiências filosóficas e, sobretudo, das ligadas a Fichte. Mais uma vez, de 
fato, na sua resposta de 27 de fevereiro, Bardili alerta Reinhold para não trocar as suas experiências filosóficas precedentes pelo ponto de vista do realismo lógico (BW, p. 125). A afirmação do pensamento como princípio estruturante da realidade significa, antes de mais nada, a consciência de que o pensamento individual pressupõe a consciência imediata de um ser, e que a consciência desta antecedência do ser relacionada ao pensar subjetivo resultaria "no mais alto realismo" (BW, p. 126).

O ser a que Bardili faz referência, todavia, não é expressão de uma determinação ou de uma possibilidade individual. Trata-se, antes, de uma totalidade (BW, p. 126), à qual é possível referir toda determinação e distinção ulterior, capaz de caracterizar o que chamamos de realidade e de mundo (BW, p. 126) ${ }^{17}$, cuja determinação subjetiva só pode ser reconduzível a uma imagem da fantasia. $\mathrm{O}$ mesmo discurso pode ser estendido para o pensamento. Não se trata, para Bardili, de uma faculdade absolutamente subjetiva, e sim de uma racionalidade estendida também além da esfera humana, que abrange também o mundo vegetal e animal (BW, p. 127). O pensamento subjetivo seria apenas o resultado de um processo onde a racionalidade se eleva à consciência acabada do princípio do real (BW, p. 130). Como salienta Bardili, trata-se de algo que se evidencia quando reconhecemos algo na vida do outro que o identifica conosco e que, no caso da comunicação intersubjetiva, torna possível uma compreensão recíproca. Esta não implica uma anulação da diversidade dos sujeitos. "Se tem que haver uma compreensão recíproca", escreve Bardili, "então em quem fala e em quem escuta tem que haver algo pressuposto de idêntico e impenetrável, pelo menos uma palavra" (BW, 132-133). Por causa disso, um autêntico filosofar tem que se diferenciar platonicamente da filodoxia, na medida em que não é uma visão da multiplicidade da experiência, e sim uma visão da imutabilidade e verdade do ser na sua essência ${ }^{18}$. A partir desta resposta, Reinhold pode se tornar consciente de que o pensamento filosófico e entendimento natural,

17 Trata-se de uma perspectiva desenvolvida no âmbito da discussão contemporânea por Hogrebe, 2014, p. 317.

18 Platão, República, 480a. 
Não são diferentes e podem ser diferenciados porque trocam as representações filosóficas da experiência e da consciência moral com a própria consciência moral. Ademais, a filosofia, que até agora as trocava com o conhecimento filosófico, tornava-as subjetivas, enquanto as representações ordinárias da experiência e da consciência moral tornam-se objetivas (BW, 118, n.).

Com isso, concordamos com Bardili, de que a filosofia como representação do pensamento, não apenas não seria necessária, como também enganosa. Filosofar significa renunciar esta representatividade para se reconhecer como parte de um todo mais amplo, como um instrumento para concretizar a representação do universo e o reconhecimento da manifestação de Deus na natureza (BW, p. 121 n.).

No entanto, ao longo de seu re-pensamento e sistematização do realismo bardiliano, Reinhold não entende este reconhecimento como algo imediato, mas como o resultado de um desenvolvimento em que não é mais o pensamento a ser assumido como primeiro princípio real, e sim como a unidade de pensamento e aplicação. Entre estes dois elementos, Reinhold estabelece uma ligação indissolúvel. De fato, não poderíamos apenas dizer que sem pensamento não poderia haver aplicação. Mas também que sem aplicação, o caráter fundamental do pensamento nunca chegaria à manifestação como seu intermediário fundamental (BLU, I, p. 102). Em contrapartida, o pensamento, através da aplicação, volta para si mesmo e se dobra em si mesmo (BLU, IV, p. 105). Mas não encontra a si mesmo apenas como pensamento, e sim como pensamento aplicado, e entende a condição da sua aplicação "não absolutamente como mera condição do mero pensamento, e sim como a condição determinada do Prius kat'exoken" (BLU, IV, p. 106). Nesta estrutura, que caracteriza o conceito da análise utilizado por Reinhold nos Beyträge para explicar, sem recorrer à mediação representativa, a passagem do pensamento à aplicação, o pensamento não se apresenta mais como uma auto identidade que se repete em todo pensamento concreto. Aparece, antes, como um processo de autorreconhecimento e de enriquecimento epistemológico. Não é por acaso que a passagem do pensamento à aplicação, entendida desta maneira, seja veículo também de um potencial catártico que permite realizar uma fenomenologia capaz de diferenciar entre o 
fenômeno da verdade e a sua aparência, ou seja, entre uma manifestação do pensamento como estrutura da realidade e a manifestação do real como produto de um pensar arbitrário e subjetivo. Porém, na definição desta estrutura, Reinhold parece não fazer mais do que usar dois termos tipicamente fichteanos. O primeiro termo é o do voltar do pensamento para si mesmo, que parece remontar o conceito fichteano de in sich zurückgehende Tätigkeit. É claro que Reinhold não entende este voltar em si mesmo como a aquisição de uma consciência representativa do pensar a partir da aplicação, mas introduzindo uma mediação na relação do pensamento com si mesmo, que não produz materialmente as determinações da realidade, e sim esquemas que nos permitem compreendê-lo e interpretá-lo. Esta conclusão pode não ser idealista, mas certamente envolve uma exigência transcendental de justificação da maneira como construímos as formas de compreensão da realidade.

O segundo termo está relacionado ao fato de que este voltar em si mesmo se realiza através (durch) da manifestação. É notório que o durch representa um elemento utilizado por Fichte para deduzir o processo de manifestação do absoluto do seu fenômeno. Contudo, de acordo com Fichte, a estrutura do Durch implica necessariamente a dedução da imprescindibilidade da consciência ao estruturar a conexão entre absoluto e fenômeno, e poderia representar uma resposta indireta e de longo prazo ao realismo racional nas exposições de doutrina da ciência, entre 1801 e 1807. Ao mesmo tempo, também para Reinhold, o recurso ao durch implica a referência a uma mediação que torna a repetição do pensamento também como um reconhecer-se. Desta maneira, ao abandonar a hipótese do idealismo racional em favor da perspectiva realista, Reinhold parece não conseguir se afastar completamente da perspectiva fichteana que tinha inspirado o seu pensamento nos anos precedentes. Entretanto, não se trata de uma dinâmica óbvia, mas rica em implicações para o desenvolvimento da filosofia clássica alemã, dos primeiros vinte anos do século XIX. 


\section{Referências}

BAGGESEN, K. Aus Jens Baggesen Briefwechsel mit Karl Leonhard Reinhold und Friedrich Heinrich Jacobi. vol. 2. Leipzig: F. M. Brodhaus, 1831.

BONDELI, M. Das Anfagsproblem bei K.L. Reinhold. Frankfurt am Main: Klostermann, 1995.

FERRAGUTO, F. A reflexão sobre a natureza e o problema da aplicação. Entre realismo racional e filosofia transcendental (1799-1801). Revista Dois Pontos, v. 12 , n. 2, p. 27-43, 2015 a.

FERRAGUTO, F. Ser, saber, pensamento. A confrontação de Fichte com o relismo racional de Reinhold e Bardili. Revista Aurora, v. 27, n. 42, p. 819-840, 2015 b.

FERRAGUTO, F. Fichte e o realismo racional. Perspectivas praticas. Revista Estud(i)os sobre Fichte, n. 13, p. 1-20, 2017.

FINCHAM, R. The Impact of Aenesidemus upon Fichte and Schopenhauer. Pli: The Warwick Journal of Philosophy, n. 10, p. 96-126, 2000.

FICHTE, J. G. Gesamtausgabe der Bayerischen Akademie der Wissenschaften. Stuttgart-Bad Cannstatt: Fromman Holzboog, 1962-2014.

HOGREBE, W. Echo des Nictswissens. Berlin: De Gruyter, 2014.

IVALDO, M. Riabilitazione di Karl Leonhard Reinhold? Due recenti pubblicazioni in Italia. Rivista di Storia della Filosofia, n. 1, p. 89-100, 2008.

POZZO, R. Introduction in Philosophiam. Firenze: La nuova Italia, 1992.

REINHOLD, K. Beyträge zur leichtern Uebersicht des Zustandes der Philosophie beym Anfange des 19. Jahrhunderts. Hamburg: Perthes, 1801-1803 (= BLU, I-VI).

REINHOLD, K. L. Ueber die Paradoxien der neusten Philosophie. Hamburg: Perthes, 1799 (= PNP).

REINHOLD, K. L. Beyträge zur leichtern Übersicht des Zustandes der Philosophie beym Anfänge des 19. Jahrhunderts. Hamburg: Perthes, 1801-1803. 
REINHOLD, K. L. Beyträge zur Berichtigung bisheriger misverständnisse der Philosophen. (F. Fabbianelli, Ed.) Hamburg: Meiner, 2004.

REINHOLD, K. L.; BARDILI, G. Briefwechsel ueber das Wesen der Philosophie. Hamburg: Perthes, 1804 (= BW).

VALENZA, P. Reinhold e Hegel. Padova: CEDAM, 1994.

VALENZA, P. Oltre la soggettivitá finita. Padova: Cedam, 2003.

VALENZA, P. Per una bibliografia recente su Reinhold. Il punto su una riscoperta. Archivio di Filosofia, p. 397-407, 2005.

Recebido: 23/08/2018

Received: 08/23/2018

Aprovado: 20/09/2018

Approved: 09/20/2018 
